\title{
A multi-decadal meridional displacement of the Subpolar Front in the Newfoundland Basin
}

\author{
I. Núñez-Riboni ${ }^{1, *}$, M. Bersch ${ }^{2}$, H. Haak ${ }^{1}$, J. H. Jungclaus ${ }^{1}$, and K. Lohmann ${ }^{1}$ \\ ${ }^{1}$ Max-Planck-Institut für Meteorologie, Bundesstr. 53, 20146 Hamburg, Germany \\ ${ }^{2}$ Institut für Meereskunde, Universität Hamburg, Bundesstr. 53, 20146 Hamburg, Germany \\ *now at: Johann Heinrich von Thünen-Institut für Seefischerei, Palmaille 9, 22767, Hamburg, Germany \\ Correspondence to: I. Núñez-Riboni (ismael.nunez-riboni@vti.bund.de)
}

Received: 9 February 2011 - Published in Ocean Sci. Discuss.: 28 February 2011

Revised: 23 January 2012 - Accepted: 4 February 2012 - Published: 15 February 2012

\begin{abstract}
Observations since the 1950s show a multidecadal cycle of a meridional displacement of the Subpolar Front (SPF) in the Newfoundland Basin (NFB) in the North Atlantic. The SPF displacement is associated with corresponding variations in the path of the North Atlantic Current. We use the ocean general circulation model MPIOM with enhanced horizontal and vertical resolutions and forced with NCEP/NCAR reanalysis data to study the relation of the SPF displacement to atmospheric forcing, intensities of the subpolar gyre (SPG) and Meridional Overturning Circulation (MOC), and Labrador Sea Water (LSW) volume. The simulations indicate that the SPF displacement is associated with a circulation anomaly between the SPG and the subtropical gyre (STG), an inter-gyre gyre with a multidecadal time scale. A sensitivity experiment indicates that both wind stress curl (WSC) and heat fluxes (which match LSW changes) contribute to the circulation anomalies in the frontal region and to the SPF displacement. An anticyclonic inter-gyre gyre is related to negative WSC and LSW anomalies and to a SPF north of its climatological position, indicating an expanding STG. A cyclonic inter-gyre gyre is related to positive WSC and LSW anomalies and a SPF south of its climatological position, indicating an expanding SPG. Therefore, the mean latitudinal position of the SPF in the NFB (a "SPF index") could be an indicator of the amount of LSW in the inter-gyre region. Spreading of LSW anomalies intensifies the MOC, suggesting our SPF index as predictor of the MOC intensity at multi-decadal time scales. The meridional displacement of the SPF has a pronounced influence on the meridional heat transport, both on its gyre and overturning components.
\end{abstract}

\section{Introduction}

The Subpolar Front (SPF) separates the cold and less saline waters of the subpolar gyre (SPG) from the subtropical waters. It is associated with the North Atlantic Current (NAC), which transports warm and saline waters from the subtropics to the subpolar region. The SPG is a region of strong interaction between ocean and atmosphere that includes the formation of Labrador Sea Water (LSW) in the Labrador Sea. Mixing of LSW with dense Nordic Seas overflows forms North Atlantic Deep Water (NADW), feeding the lower branch of the Atlantic Meridional Overturning Circulation (MOC). Additionally, increased production of LSW intensifies the SPG strength and, therefore, an index of SPG variations could be used to monitor the overturning circulation in the subtropics (Böning et al., 2006).

At the decadal and longer time scales, the variability of the SPG has been found to be mainly driven by buoyancy fluxes modulated by the North Atlantic Oscillation (NAO; Eden and Jung, 2001): Changes from periods of lower to higher NAO index are associated with stronger westerlies and increase of latent and sensible heat fluxes from the ocean to the atmosphere over the SPG in winter (Cayan, 1992). This cooling intensifies the deep convection, forming LSW, and increasing the volume of intermediate water in the gyre's interior. Owing to these density changes, acceleration of the baroclinic component of the SPG has been observed one to two years after a switch to positive NAO (Curry and McCartney, 2001). Lagging the change to positive NAO by three years, the change of density structure of the SPG has been simulated to intensify also its barotropic component, due to 
coupling of the baroclinic structure and the barotropic mode (Eden and Willebrand, 2001). In agreement with these notions, Häkkinen and Rhines, 2004, state that weakening of the SPG in the 1990s is not attributable to wind stress curl (WSC) changes but to decreasing buoyancy fluxes in the subpolar region.

While there is a rough agreement about the mechanisms ruling the SPG intensity, there is still ambiguity about the influence of these mechanisms on the SPG geometry, i.e. on displacements of the Subpolar Front. In response to a decreasing NAO, the isoline of zero WSC displaces southward, yielding a cyclonic circulation anomaly between the SPG and subtropical gyre (STG): an inter-gyre gyre (Marshall et al., 2001). Eden and Greatbatch, 2003, agree on the influence of the WSC on the formation of the inter-gyre gyre and state that it dominates the variability at interannual time scales. This circulation anomaly advects more cold subpolar water into the subtropical region in the Newfoundland Basin (NFB), displacing the SPF southwards, and more warm subtropical water into the subpolar region in the eastern North Atlantic, displacing the SPF north-westwards (Eden and Willebrand, 2001). Consistently, Bersch et al., 1999, observed a westward displacement of the SPF in the eastern North Atlantic during the 1990 s as the NAO decreased. The impact of this front displacement on the volume transport of subtropical waters at the interannual to inter-decadal time scales has been discussed by Hátún et al., 2005. In the western North Atlantic, a southward shift of the SPF at $55^{\circ} \mathrm{W}$ was observed between 1976 and 1977 when the NAO index dropped (McCartney et al., 1980). Displacements of the Gulf Stream axis between 50 and $70^{\circ} \mathrm{W}$ have been found to be in phase with the NAO (Joyce et al., 2000) or to follow it by 11 to 18 months (Frankignoul et al., 2001). Bersch, 2002, observed a similar south-eastward displacement of the SPF in the NFB, 1.5 years after the drop of the NAO index during the 1990s.

SPF displacements at longer time scales, their causes and their impact on the meridional heat transport (MHT) have, so far, not been investigated in detail. The present study tries to fill this gap focusing on the multi-decadal variability in the subpolar region of the North Atlantic by using an extended database of hydrographic observations and ocean model simulations. This paper is structured as follows: In Sect. 2 we present the observational data and in Sect. 3 the model simulations and analysis methods. The simulated and observed multi-decadal SPF displacements during the last five decades are presented in Sect. 4. In Sect. 5.1 we contrast LSW spreading and changes of WSC to explain the multi-decadal SPF displacement in the NFB. In the following we discuss the relation between the meridional position of the SPF in the NFB and LSW volume (Sect. 5.2), MOC intensity (Sect. 5.3) and MHT (Sect. 5.4). In Sect. 6 we present a summary and the conclusions.
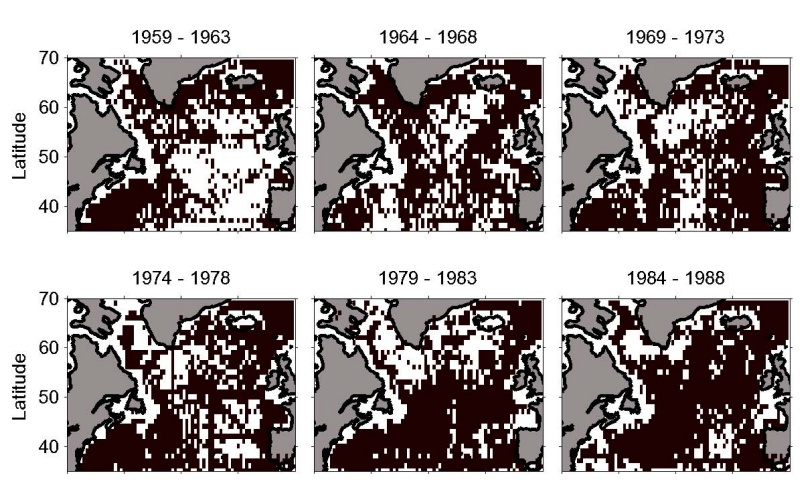

$1979-1983$
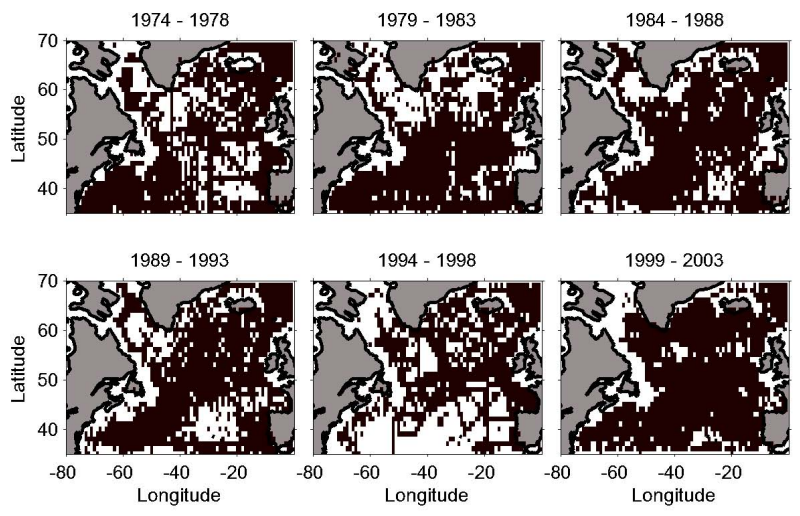

Fig. 1. Data distribution in the study area. Bins of $1^{\circ} \times 1^{\circ}$ with at least one observation of the CliSAP data set in the period shown at the top of each panel are marked black. The panels correspond to those of Fig. 3a below.

\section{Observations}

The observational data set from the CliSAP (Integrated Climate System Analysis and Prediction) data center used in this study consists of about 800000 hydrographic stations with water samples and/or CTD measurements between 1950 and 2006 in the region of 35 to $70^{\circ} \mathrm{N}$ and $85^{\circ} \mathrm{W}$ to $10^{\circ} \mathrm{E}$ (Fig. 1). Data sources are WOD05 (World Ocean Database 2005; Boyer et al., 2006), HydroBase2 (Curry, 2002), ICES (International Council for the Exploration of the Sea), WOCE (World Ocean Circulation Experiment), CLIVAR (Climate Variability and Predictability Programme), and others. Additionally, about 30,000 float profiles from the Argo project (pilot program of the Global Ocean Observing System) between 1998 and 2006 were used.

The temperature and salinity data were inspected for erroneous data, then selected at 82 pressure levels and averaged for each year in $1^{\circ} \times 1^{\circ}$ geographical boxes. Each box time series was then filtered with a 3-year running mean, yielding 55 3-year intervals between 1950 and 2006, which increases the spatial data density in each interval. For this study, the data at $500 \mathrm{~m}$ depth, where the seasonal signal is relatively small, were selected and objectively interpolated horizontally for each 3-year interval. The observations were finally detrended and filtered with a Lanczos filter with a cut-off period of 25 years to extract the multi-decadal signal, which is dominant in the subpolar region. 


\section{Model}

\subsection{Model set-up and analysis methods}

The model used in the present study is the ocean general circulation model MPIOM of the Max Planck Institute for Meteorology (Marsland et al., 2003) with global domain. It is a primitive equation model with hydrostatic and Boussinesq approximations, Arakawa-C grid, z-coordinate, free surface, bottom boundary layer scheme and embedded sea-ice dynamics and thermodynamics. The model has been used in a number of previous studies (Haak et al., 2003; Jungclaus et al., 2006; Olsen et al., 2008; Zhu and Jungclaus, 2008).

The applied model set-up features quasi-homogenous horizontal resolution of $0.4^{\circ}$ and 80 vertical layers. We start the model with climatology conditions from Levitus, 1994, and spin it up for 700 years, using a climatological annual composite of sea surface fluxes and wind stress (OMIP; Röske, 2010 ) and surface salinity restoring of 35 days. Thereafter, we force the ocean using 24-hourly NCEP/NCAR data (Kalnay et al., 1996) from 1948 to 2008 subsequently for three times. Short wave radiation of the NCEP data are scaled by a factor of 0.89 (Haak et al., 2003). The last cycle of these simulations is discussed in this paper. Because model and observations differ strongly in the 1950s as the simulation adjusts to the forcing, we discuss only the results from 1958 onward.

We interpolate simulated salinity, temperature, and stream function onto a $1^{\circ} \times 1^{\circ}$ regular grid and average them to annual means. To analyse these data, the usual approach of characterising oceanic and atmospheric variables with indices is followed: We define an index for the intensity of the SPG with the mean barotropic stream function between 45 and $65^{\circ} \mathrm{N}$ and 20 to $60^{\circ} \mathrm{W}$. We multiply this index by minus one to obtain a strong SPG related to a positive index and a weak SPG to a negative index.

We define the intensity of the MOC in the subpolar region as the strength of the zonally integrated stream function at $47^{\circ} \mathrm{N}$ and $1400 \mathrm{~m}$ depth. A similar index for the MOC has been chosen by Eden and Willebrand, $2001\left(52^{\circ} \mathrm{N}\right.$ and $1500 \mathrm{~m})$ and by Eden and Greatbatch, $2003\left(47.9^{\circ} \mathrm{N}\right.$ and $1270 \mathrm{~m})$.

For every time step, we define the SPF at $500 \mathrm{~m}$ depth as the region with the magnitude of the horizontal density gradient larger than its space mean plus $1 / 4$ of its standard deviation. Only data between 30 to $50^{\circ} \mathrm{W}$ and 35 to $55^{\circ} \mathrm{N}$ are considered. Varying the size of this box in meridional direction gave similar results. We call the mean latitude of the SPF the SPF index. Increase of the SPF index indicates a general northward displacement of the SPF in the NFB, decrease of the index indicates southward displacement. A SPF index for the observations has been computed in the same way.

We study the atmospheric forcing with the NAO index which is calculated as the principal component time series of the leading empirical orthogonal function (EOF) of sea level pressure anomalies over the Atlantic sector $\left(20\right.$ to $80^{\circ} \mathrm{N}$ and $90^{\circ} \mathrm{W}$ to $40^{\circ} \mathrm{E}$ ) from December to March (Hurrell, 1995; data provided by the Climate Analysis Section of the National Center for Atmospheric Research, Boulder, USA).

To define LSW in the model we study first the salinity minimum with $\Theta / \mathrm{S}$-diagrams and vertical sections of salinity. From these plots, several isopycnals above and below the salinity minimum are chosen and tracked during the last NCEP experiment. We choose as LSW bounds the isopycnals closest to the salinity minimum but that diverge during winter in the Labrador basin (potential density anomalies $\sigma_{0}=27.60 \mathrm{~kg} \mathrm{~m}^{-3}$ and $\left.\sigma_{2}=36.96 \mathrm{~kg} \mathrm{~m}^{-3}\right)$.

As the observations, we detrend and then filter the indices and the spatially interpolated model data with a Lanczos filter and a cut-off period of 25 years. The variance of the yearly averaged indices explained by the filtered indices is $39 \%$ for the MOC, $51 \%$ for the SPG and $54 \%$ for the SPF. All anomalies shown in the figures are referred to the 19582006 mean.

\subsection{Model evaluation}

The global ocean model features an eddy-permitting resolution of $0.4^{\circ}$ that allows for a good representation of topographic features, such as the Florida Strait and the Greenland-Scotland Ridge with its overflow conduits. However, resolution issues remain in the proper representation of Mediterranean Overflow Water (MOW), which is too warm and too salty in the model. Another persisting deficit is a too zonally-oriented NAC. Notwithstanding these deficiencies, MPIOM is able to reproduce correctly the mean state of the subpolar North Atlantic, as shown by comparing model output with CliSAP data, as well as with previous studies: The time-average simulated SPG spans from 44 to $65^{\circ} \mathrm{N}$ and reaches maximum annual strength of about $30 \mathrm{~Sv}$ $\left(1 \mathrm{~Sv}=1\right.$ Sverdrup $\left.=10^{6} \mathrm{~m}^{3} \mathrm{~s}^{-1}\right)$. This value is inside the range of previous estimates from observations, from 27 to 34 Sv (Clarke, 1984; Bersch, 1995; Bacon, 1997). Vertical sections of salinity feature a well defined salinity minimum related to LSW (not shown), yet shallower than the climatological depth from observations. The mean zonal stream function shows that the MOC strength at $26^{\circ} \mathrm{N}$ and $1000 \mathrm{~m}$ depth is approximately $12.8 \mathrm{~Sv}$, which is weaker than the observed estimates of $18.7 \pm 5.6 \mathrm{~Sv}$ (Cunningham et al., 2007) or $18.5 \pm 4.9 \mathrm{~Sv}$ (Kanzow et al., 2010). However, our MOC intensity is not particularly weak in comparison to other models: From the seven models compared by Griffies et al., 2009, only two show a stronger MOC than MPIOM.

Further comparison of the model output with previous studies and with CliSAP observations indicates that the model represents the interannual and decadal variability of the SPG reasonably good: e.g., for the stratification of the SPG (Bersch et al., 2007), for the potential energy anomaly (PEA; Curry and McCartney, 2001, Kieke et al., 2007; upper left panel in Fig. 2), and for the simulated Sea Surface Height 

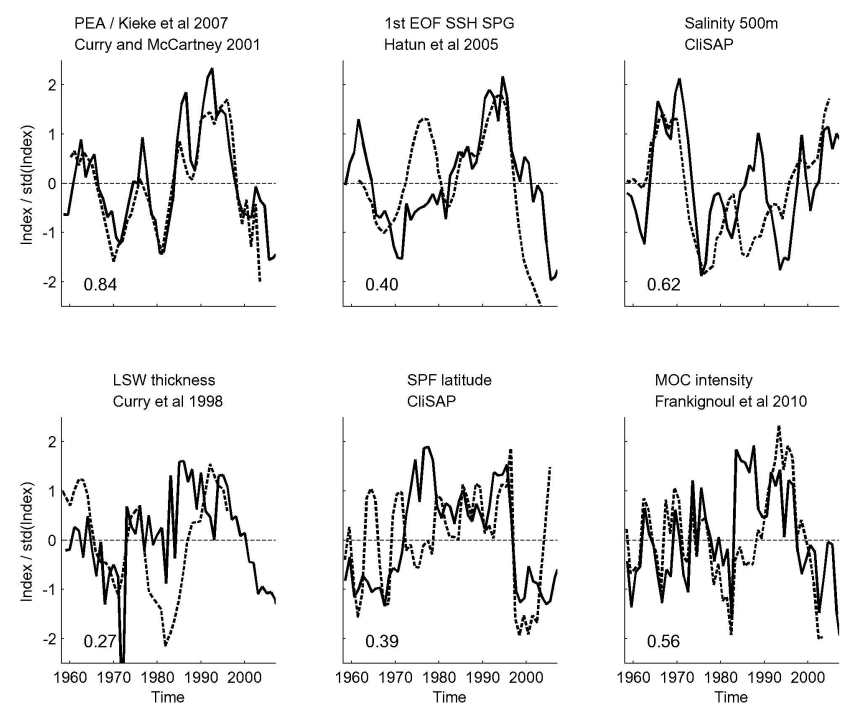

Fig. 2. Comparison between our simulated (solid lines) and observed or previously simulated (dashed lines) indices derived from non-filtered annual data of PEA (upper left panel), gyre intensity index as first EOF of SSH (upper middle panel), mean salinity at $500 \mathrm{~m}$ depth in the subpolar region (upper right panel), LSW thickness in its formation area (lower left panel), mean latitudinal position of the SPF in the NFB (lower middle panel) and MOC intensity (lower right panel). The numbers inside the panels are the correlation between the corresponding solid and dashed curves.

(SSH) (Hátún et al., 2005; upper middle panel in Fig. 2). Modelled salinity at $500 \mathrm{~m}$ depth in the subpolar region (averaged between 60 and $10^{\circ} \mathrm{W}$ and between 45 and $65^{\circ} \mathrm{N}$ ) matches the CliSAP observations well (upper right panel in Fig. 2), but the arrival of low salinity waters of the 1980s as reported by Belkin et al., 1998, is unfortunately missed by the model.

The model roughly reproduces observations from Curry et al., 1998 (lower left panel in Fig. 2): decrease of LSW from the 1960 until reaching a minimum in 1970 and an increase towards the 1990s. However, and despite our efforts to objectively choose the isopycnals defining LSW (Subsect. 3.1), the match is poor during the 1980s. This could be due to the absence in the model of the large salinity anomaly in the 1980s and the corresponding convection suppression. LSW thickness has been calculated in the region of maximum winter convection (which is not necessarily the same in model and observations). On the other hand, it is also possible that the negative LSW thickness anomaly in the 1980s from Curry et al., 1998, is overestimated: it is considerably larger than the negative anomaly of the 1970s, while the PEA anomalies of the 1970s and the 1980s are of similar magnitude. The SPG intensity and subpolar salinity show even a larger negative anomaly in 1970s than in the 1980s.

Our modelled mean meridional position of the SPF in the NFB is roughly in phase with the observed one, even though it differs in amplitude sometimes like in 1965 or in the 1970s (lower middle panel in Fig. 2). The intensity of the MOC (lower right panel in Fig. 2) is in good agreement with the MOC index of Frankignoul et al., 2010. The mismatch in the 1980s could be also due to the absence of the large salinity anomaly, convection suppression and the corresponding negative LSW volume anomaly. Sea ice concentration and extension (not shown) match observations of the British Meteorological Office (Rayner et al., 2003).

Finally, the overall relations between SPG, STG, MOC and NAO are in agreement with previous studies: SPG and STG intensities are nearly in phase (Curry and McCartney, 2001). A few years after a change to positive NAO, SPG (Eden and Willebrand, 2001) and MOC (Eden and Greatbatch, 2003; Brauch and Gerdes, 2005; Böning et al., 2006) intensify, indicating that both are nearly in phase (Frankignoul et al., 2010).

\section{Results}

Figure 3 shows the low-pass filtered observed (panel a) and modelled (panel b) salinity anomalies at $500 \mathrm{~m}$ depth for selected years, which are representative for the upper layer of the SPG. Temperature anomalies are not shown here since they are strongly correlated to salinity anomalies. The evolution of the salinity anomalies in the simulation and observations from the 1960s to 2000s is the following: There is an almost full cycle from anomalously high salinity in the entire SPG region in the 1960s to much fresher conditions in the 1970s and 1980s and back to more saline conditions in the 1990s. More regionally, in the NFB, a negative salinity anomaly during the $1950 \mathrm{~s}$ and $1960 \mathrm{~s}$, centred near $45^{\circ} \mathrm{N}$ and $40^{\circ} \mathrm{W}$ becomes positive from the middle 1970 s on to become negative again in the middle 1990s. Thus, salinity in the subpolar region evolves out of phase to the one in the NFB.

The general agreement between simulation and observations is reasonable but there are obvious differences in certain regions. E.g. the discrepancies in the Iceland and West European Basins (upper right panels in Fig. $3 a$ and b) can be related to the too zonal NAC in the model. The resemblance between observed and modelled salinity in the NFB and the western SPG region is reasonably good. Therefore, we concentrate in this study on the SPF displacement in the NFB.

To study the time evolution of the anomalies, we show in Fig. 4 the indices for NAO and our modelled oceanic variables. A complete multi-decadal cycle of the indices is found in the last 50 years of the experiment: The NAO (panel a) increases from anomalously low values in the 1960s to its maximum in 1991 and finally decreases to the end of the record. The MOC (panel b) is anomalously slow until 1975, when it starts to increase to its maximum in 1988, to slow down to the end of the record. The SPG intensity (panel c) decreases 

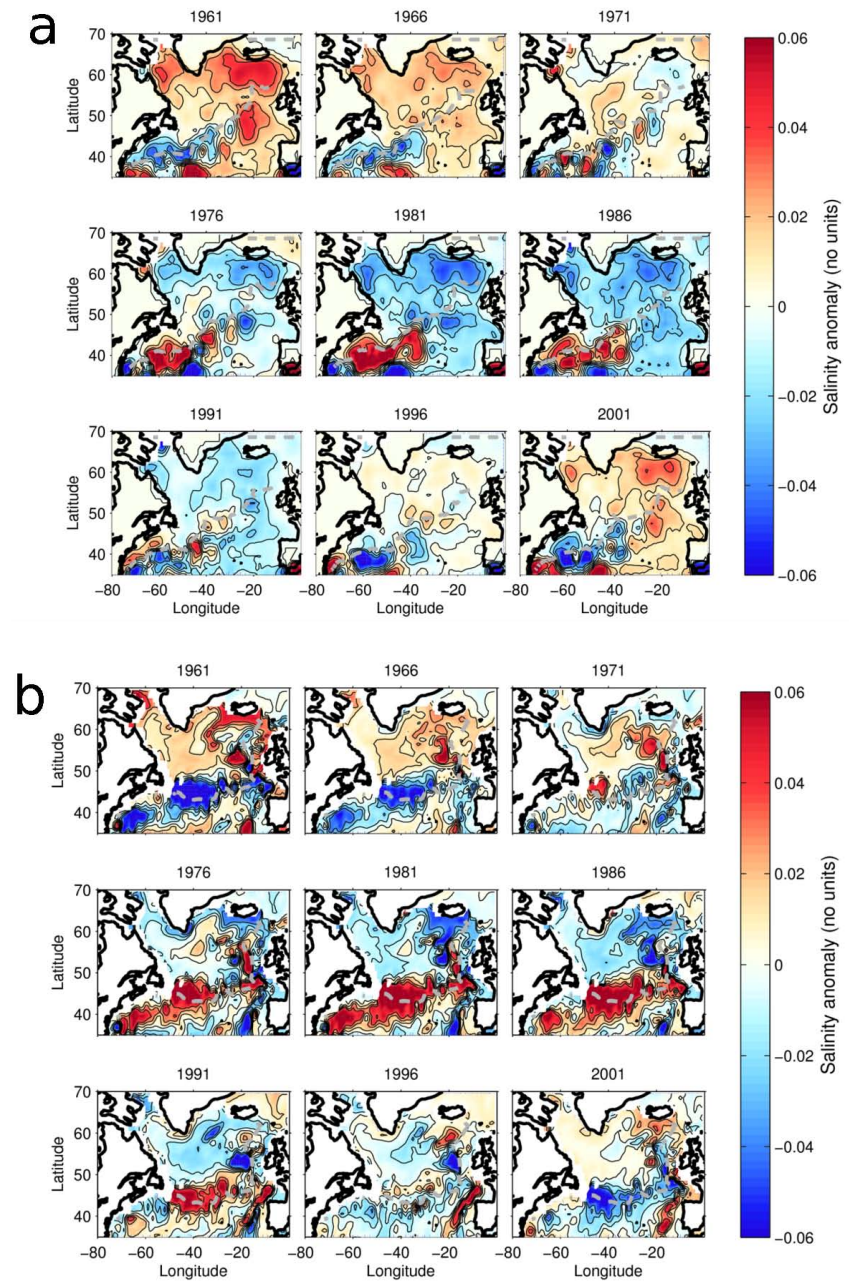

Fig. 3. Low-pass filtered observed (a) and simulated (b) salinity anomalies (referred to the 1958-2006 mean) at 500 m depth for various time lags around 1981 (central panel in each figure), the year in which the SPF in the NFB reaches maximum northern latitude. The observations have been filtered spatially with a boxcar window $\left(5^{\circ}\right.$ in the zonal direction and $3^{\circ}$ in the meridional one). The colour bars indicate the magnitude of the anomalies. The grey dashed curves show the position of the SPF for each year.

to its minimum in 1975, increases to its maximum in 1992 and then decreases again to the end of the record. The SPF in the NFB (panel d) is south of its mean latitude during the 1960s as it shifts northwards to its maximum latitude in 1981 (before NAO, MOC and SPG maxima). Then, the front displaces southwards to the end of the record.

These salinity and temperature changes in the subpolar region are associated with MHT changes. The temporal evolution of the total MHT is characterised by pronounced variations with the largest amplitudes in the SPF region (Fig. 5a). Generally, negative anomalies prevail during the 1970s and early 1980s and positive anomalies can be seen through the 1950s and for the 1990s for all latitude bands. The slope
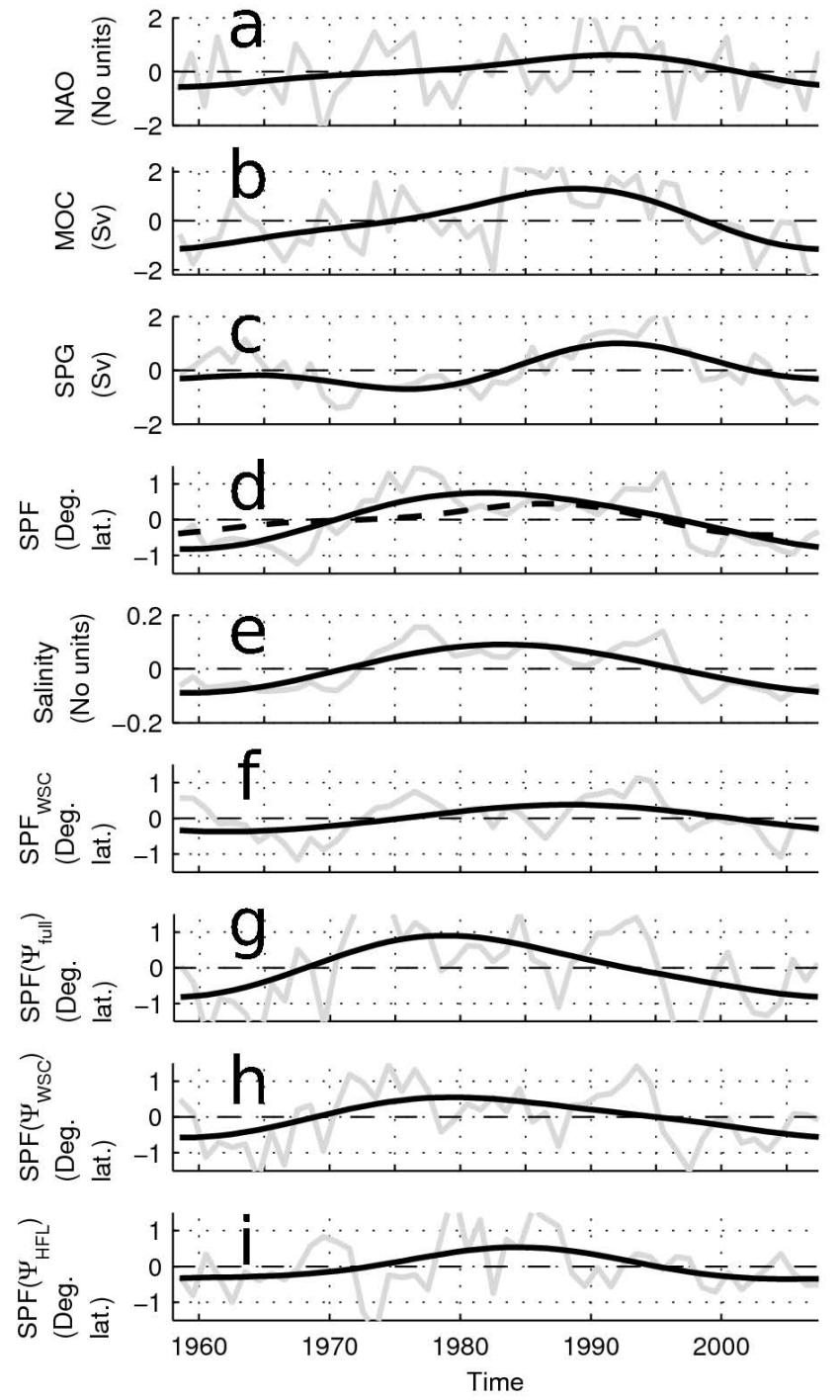

Fig. 4. Anomalies of annual averaged (grey curves) and low-pass filtered (black curves) indices used in the present study: NAO (panel a; no units), MOC intensity at $47^{\circ} \mathrm{N}$ (panel b; Sv), SPG intensity (panel c; Sv), SPF index of full forcing experiment (panel d; degrees of latitude), mean salinity in the frontal region of the NFB (panel e; no units), SPF index of WSC component (panel f; degrees of latitude) and SPF index calculated with the isoline of zero stream function for the full forcing experiment (panel g), WSC (panel h) and HFL components (panel i; degrees of latitude in the three cases). The thick dashed curve in panel $\mathrm{d}$ is the low-pass filtered SPF index from the observations.

of the isolines indicates southward propagation of anomalies north of the SPF and northward propagation south of the SPF. A decomposition of the MHT into gyre and overturning components (Fig. 5b and c) reveals that these propagations result mainly from the gyre MHT. Overturning MHT anomalies occur most pronounced directly at the SPF and are almost out of phase with the gyre MHT anomalies. South of 

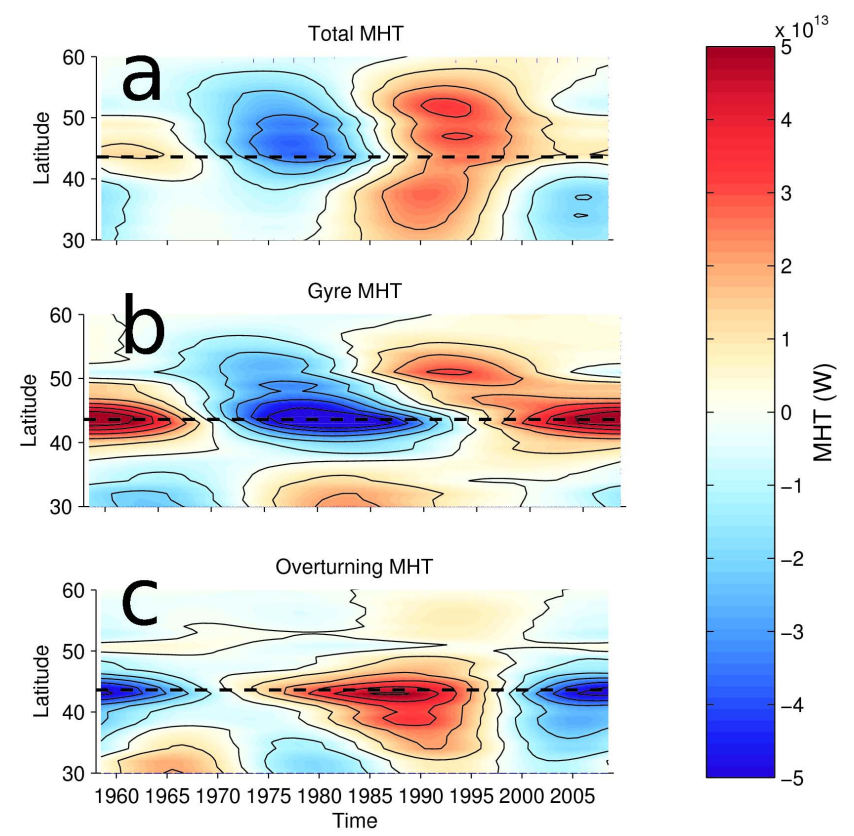

Fig. 5. Hovmöller diagrams of anomalous total (a), gyre (b) and overturning (c) MHT (watts) against latitude. The mean latitude of the SPF in the NFB $\left(44^{\circ} \mathrm{N}\right)$ is shown with a dashed line in all the panels. Red indicates northward heat transport, blue southwards. A colour bar shows the magnitude of the MHT anomalies.

$40^{\circ} \mathrm{N}$, overturning and gyre MHT anomalies seem to contribute with similar amounts to the total MHT variations, while the gyre MHT anomalies dominate the total MHT variations north of the SPF.

\section{Discussion}

The salinity changes in the NFB (Fig. 3) correspond to a multi-decadal displacement of the SPF: Positive temperature and salinity anomalies arise due to advection of warm salty subtropical water as the SPF shifts northwards, while negative anomalies arise due to cold fresh subpolar water as the SPF shifts southwards. Figures 3 and $4 d$ show a complete multi-decadal cycle of the SPF displacement in the NFB: The front displaces northwards from its southernmost position at the beginning of the experiment, passing its mean latitudinal position around 1967 and reaching maximum northward position in 1981 as the salinity in the NFB increases to a maximum. Then, the SPF retracts southwards to its mean latitudinal position as the salinity anomaly in the NFB reduces to zero. The front keeps displacing southwards until reaching its most southward position in 2005 as the salinity reduces to a minimum. The cycle length of the SPF meridional oscillation is on the order of 50 years.

A comparison between the SPF index and the mean salinity at $500 \mathrm{~m}$ depth in the in the NFB (42 to $46^{\circ} \mathrm{N}$ and 30
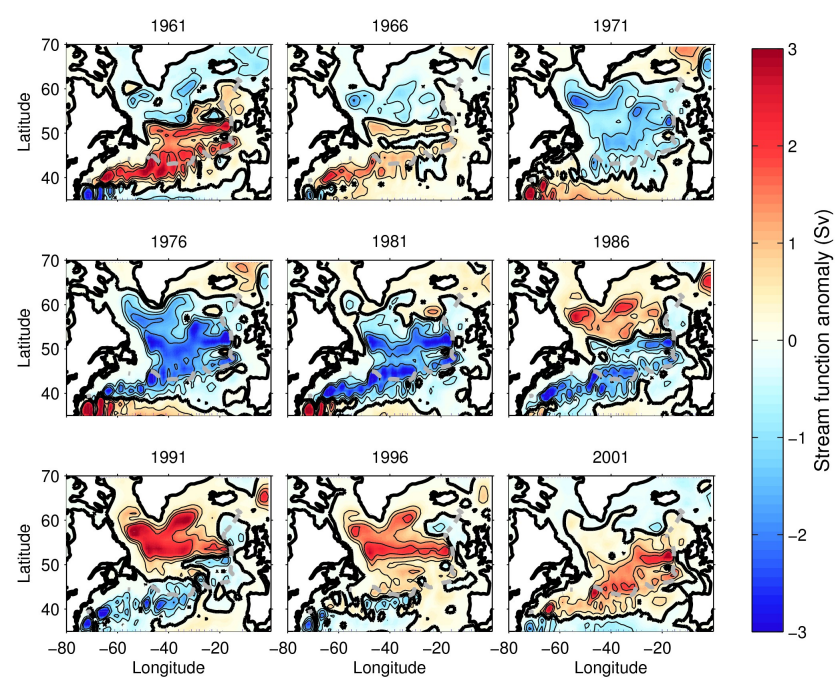

Fig. 6. As Fig. 3, but for barotropic stream function anomalies (Sv). Positive anomalies (red) are cyclonic and negative anomalies (blue) are anticyclonic.

to $50^{\circ} \mathrm{W}$; Fig. $4 \mathrm{e}$ ) confirms that the salinity anomalies from Fig. 3 are related to the front displacement. The low-pass filtered SPF index from observations (Fig. 4d, dashed curve) roughly matching the modelled one (solid curve) confirms that the model correctly reproduces the multi-decadal displacement of the front. In the following subsections we discuss possible causes for this displacement and its relation to SPG, LSW, MOC and MHT in the subpolar North Atlantic.

\subsection{Causes of the SPF displacement}

The multi-decadal displacement of the SPF and, thus, the NAC are associated with anomalies of the barotropic stream function (Fig. 6). A SPF south of its climatological position (i.e. before 1967 and after 1995; Fig. 4d) is characterised by a cyclonic anomaly overlying the SPF, while a SPF north of its climatological position (between 1967 and 1995) is characterised by an anticyclonic anomaly. This circulation anomaly is similar to the inter-gyre gyre proposed by Marshall et al., 2001, and discussed by Eden and Greatbatch, 2003, and, therefore, we will also use the term inter-gyre gyre here. Additionally, we note that our circulation anomalies propagate from the north towards the south. Analysing local trends between snapshots of Fig. 6 (not shown) indicate that the northward displacement of the SPF is related to an increasing anticyclonic inter-gyre circulation indicating a northward expansion of the STG in this region, while the southward displacement of the front occurs during periods of increasing cyclonic inter-gyre circulation, indicating a southward expansion of the SPG. The maximum northward position of the SPF occurs when the rate of change of the multi-decadal inter-gyre gyre is at minimum. 


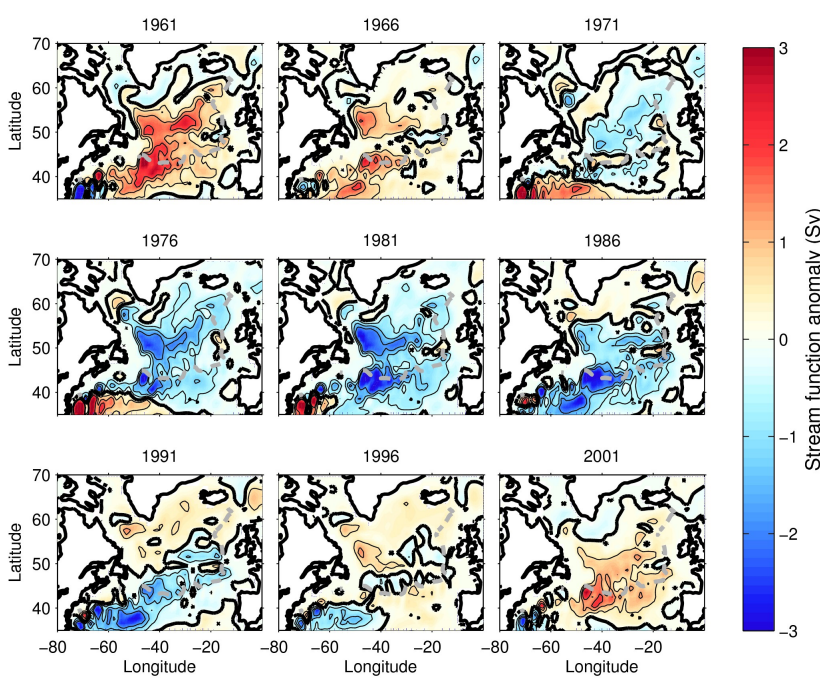

Fig. 7. As Fig. 6, but for barotropic stream function anomalies (Sv) of a sensitivity experiment with variable wind and climatological heat fluxes (WSC circulation component).

We turn now our attention to the mechanisms driving these circulation changes. Häkkinen and Rhines, 2004, compare the dynamic consequences of buoyancy forcing and barotropic and baroclinic response to local WSC changes. They state that an increase of SSH in the subpolar region during the second half of the 1990s parallels the warming in the central SPG as a result of the relaxation of the water column after shut-down of intense winter convection in the previous years. Similarly, Eden and Jung, 2001, have shown with sensitivity experiments that the multi-decadal variability of the SPG would be driven by heat fluxes rather than by changes of WSC. On the other hand, Bersch et al., 1999, Frankignoul et al., 2001, and Bersch, 2002, have suggested changes of WSC modulated by the NAO at interannual time scales as cause for the SPF displacement during the 1990s. In the specific case of the eastern North Atlantic, the front displacement has been attributed to a WSC-generated intergyre gyre by Eden and Willebrand, 2001, and Herbaut and Houssais, 2009. At the decadal time scale, Häkkinen et al., 2011, stress also the importance of WSC changes on the SPF shift in the eastern North Atlantic. Therefore, the two main candidates responsible for the circulation changes of Fig. 6 are WSC and heat-flux changes, the latter being reflected by changes in convection and amount of LSW.

To study the influence of possible multi-decadal changes of WSC on the SPF displacement, we have performed a sensitivity experiment with variable wind and climatological heat fluxes (similar to Eden and Willebrand, 2001). We call the stream function of this experiment the "WSC component" of the circulation. Circulation anomalies of the WSC component (Fig. 7) have similar amplitudes (with differences of around $1 \mathrm{~Sv}$ ) and are in phase with the anomalies of the full

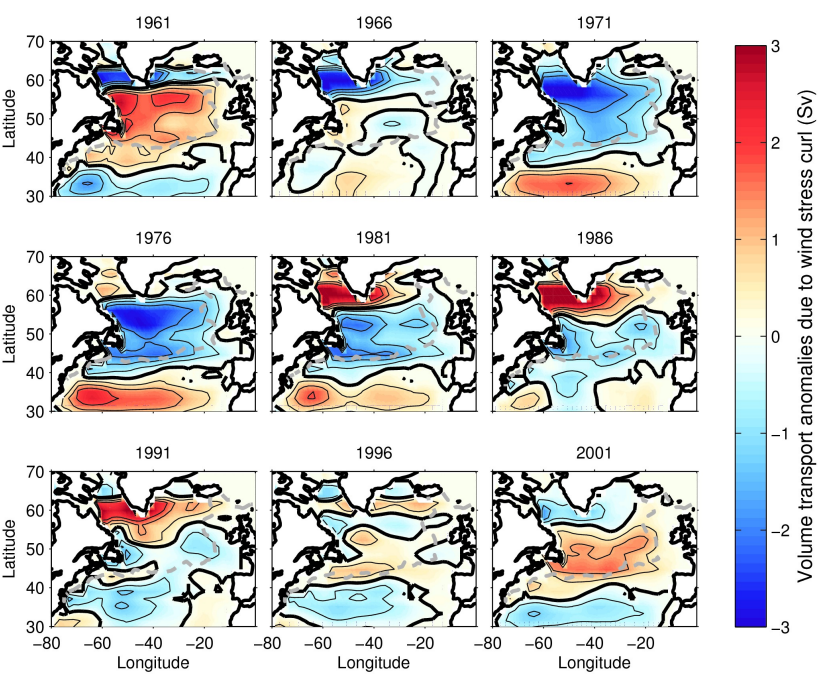

Fig. 8. As Fig. 6 but for transport anomalies derived from the Sverdrup relation $(\mathrm{Sv})$.

forcing experiment (Fig. 6), particularly in the inter-gyre region (between 35 and $55^{\circ} \mathrm{N}$ ): Positive circulation anomalies in the 1960s (upper left and upper middle panels) and after 1996 (lower middle panel), as the SPF is south of its climatological position, and negative anomalies from 1971 (upper right panel) to 1991 (lower left panel), as the SPF is north of its climatological position. This clearly indicates that the WSC has a large effect on the multi-decadal displacement of the SPF. This notion is supported by a large similarity with circulation anomalies from the zonally integrated WSC (Sverdrup, 1947) from NCEP data (Fig. 8), considering the limitations of the theory near the boundaries: The circulation anomalies in both cases have the same amplitude and phase in the inter-gyre region. Additional support of the large WSC influence on the SPF displacement is obtained with the SPF index from the sensitivity experiment $\left(\mathrm{SPF}_{W S C}\right.$, Fig. 4f): While SPF ${ }_{W S C}$ lags the SPF index of the full forcing experiment (Fig. 4d) by some years, its overall behaviour at the multi-decadal time-scale is similar.

Assuming a linear response of the driving mechanisms, the residual between the WSC contribution and the barotropic stream function of the full forcing experiment would represent the contribution by the heat fluxes (HFL). We call this residual circulation the "HFL component". Circulation anomalies of the HFL component (Fig. 9) differ from those of the WSC component (Fig. 7) in the subpolar region (more about this in Sect. 5.2), but they have similar amplitude and phase in the SPF region. Therefore, both circulation components play a similar role on the variability of the SPF displacement.

Unfortunately it is not possible to calculate a SPF index from density for the HFL component, because it is the residual between two experiments. Hence, to try to quantify the 

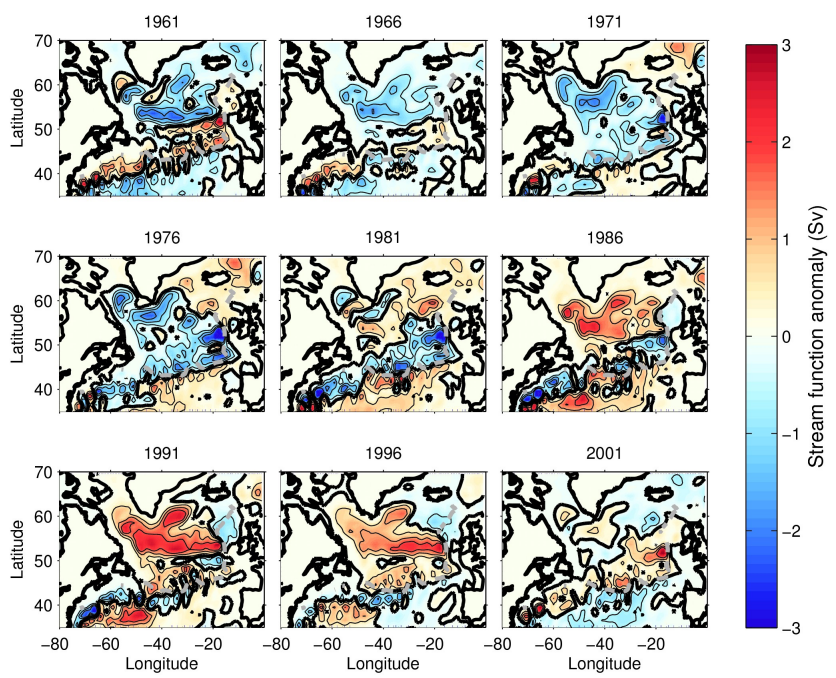

Fig. 9. As Fig. 6 but for anomalies of the residual barotropic stream function ("heat flux" circulation component), which is the difference between the WSC contribution and the full forcing experiment (Sv).

contribution of the HFL component to the SPF displacement we introduce proxy $\operatorname{SPF}(\Psi)$ indices defined by the position of the zero isoline of the barotropic stream function for each circulation component (Fig. 4g to i). Such a proxy index is justified by the great similarity between the SPF index of the full forcing experiment $\left(\operatorname{SPF}\left(\Psi_{\text {full }}\right)\right.$, Fig. $\left.4 \mathrm{~g}\right)$ and its density counterpart (Fig. 4d). The SPF index of the HFL component $\left(\operatorname{SPF}\left(\Psi_{\mathrm{HFL}}\right)\right.$, Fig. 4i) lags the WSC one (SPF $\left(\Psi_{\mathrm{WSC}}\right)$, Fig. $4 \mathrm{~h}$ ) by approximately 5 years. Despite this time lag the overall behaviour of the $\operatorname{SPF}(\Psi)$ indices of both the WSC and the HFL components matches the SPF index (Fig. 4d). Additionally, both circulation components drive a front displacement of similar amplitude, i.e. ca. 0.5 degree latitude. This suggests that the variability induced by the HFL component is of similar magnitude as the variability driven by the WSC component. Moreover, it also suggests the appealing idea that the sum of both indices yields the SPF index of the full forcing experiment (note displacement of ca. 1 degree latitude, Fig. $4 \mathrm{~d}$ and g). Finally, the $\operatorname{SPF}(\Psi)$ of the HFL component being more similar to the observed SPF index (Fig. 4d, dashed curve), with maximum in the mid-1980s, supports the notion that the HFL component plays an important role on the SPF displacement.

Therefore, the overall multi-decadal meridional displacement of the SPF in the NFB can be interpreted as the result of both WSC and HFL changes of similar magnitudes, emphasising the importance of long-term variations of WSC on the dynamics of the multi-decadal variability of the SPG. In fact, the multi-decadal variations of the WSC (not shown) are only one order of magnitude smaller than the long-term mean WSC, yielding thus transport anomalies of magnitude similar
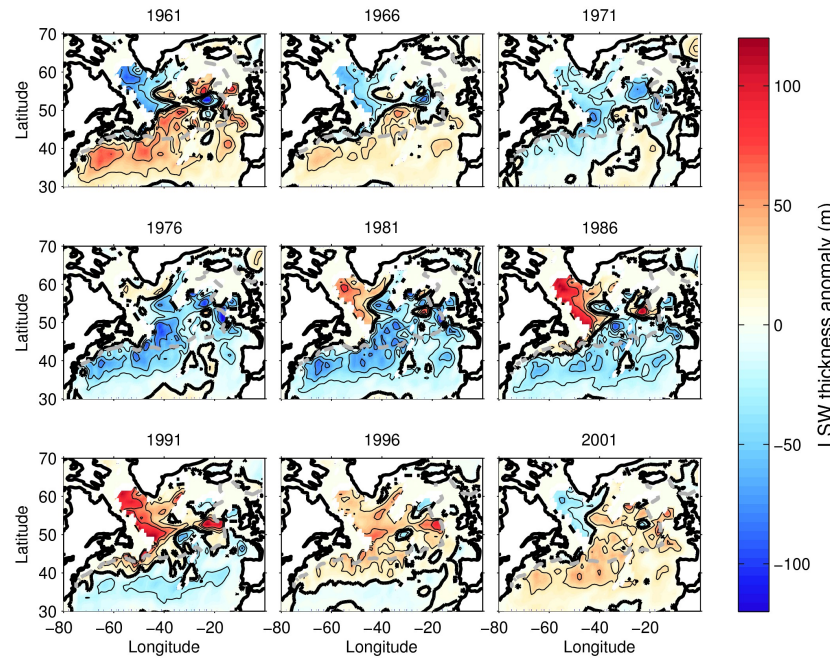

Fig. 10. As Fig. 3 but for modelled LSW thickness anomaly (m).

to those due to HFL changes (a few Sv). This notion is different to results of Eden and Jung, 2001, who stress mainly the importance of heat fluxes on the multi-decadal variability of the SPG, but similar to Häkkinen et al., 2011, who state that the shift of the SPF in the eastern North Atlantic is due to multi-decadal WSC changes.

\subsection{The SPF position as indicator for LSW volume changes}

Multi-decadal changes of LSW are shown in Fig. 10. The non-filtered changes of LSW thickness between the 1960s and 1990s (not shown) roughly match observations of Yashayaev, 2007 (his Fig. 4) in the central Labrador Sea (600 $\mathrm{m}$ and more) and all along the Labrador coast up to the Newfoundland Basin (around $300 \mathrm{~m}$ ).

A negative anomaly of LSW thickness is beginning to develop in the Labrador Basin in the 1960s (Fig. 10) when the NAO is growing negative (Fig. 4a) and convection is anomalously weak. This negative LSW thickness anomaly displaces from north-west to south-east, spreading along the SPF and further into the STG and SPG interiors, following a path similar to the one diagnosed for positive anomalies by Sy et al., 1997.

While hydrographic changes driving SPG circulation changes (Curry and McCartney, 2001; Eden and Willebrand, 2001) could arise due to other reasons, our modelled LSW changes match well the circulation anomalies due to HFL in general (Fig. 9), and particularly in the SPF region: A negative LSW anomaly in the inter-gyre region is related to an anticyclonic inter-gyre gyre and to a SPF north of its climatological position as in the 1970s and 1980s, while a positive LSW anomaly is related to a cyclonic inter-gyre gyre and a SPF south of its climatological position as in the second half of the 1990s and 2000s. The LSW thickness in the frontal 
region is at minimum roughly in 1981 when the SPF is northernmost. A close relationship between LSW and SPF in the NFB is also indicated by observations in the 1990s and early 2000s (Bersch et al., 2007). Therefore, the mean latitudinal position of the SPF in the NFB (SPF index; Fig. 4d) could be used as an indicator of the amount of LSW in this basin on a multi-decadal time scale.

\subsection{The SPF position as an indicator for the MOC intensity}

Comparison of the MOC index (Fig. 4b) with Fig. 10 shows that the negative LSW thickness anomaly in the western subpolar region up to 1976 is related to an anomalously weak MOC, while the positive LSW thickness anomaly after 1976 is related to an anomalously strong MOC. This is in agreement with LSW volume changing the zonal density gradient and, in turn, the MOC intensity (Eden and Greatbatch, 2003; Böning et al., 2006).

We study these variations of the MOC intensity in the North Atlantic analysing circulation anomalies of the MOC stream function (Fig. 11): The MOC is divided by the SPF in two regimes, with the regime in the subpolar region showing larger variability. A similar MOC anomaly spanning comparable latitudes and depths inside the subpolar region is found by Eden and Greatbatch, 2003, and by Gulev et al., 2003, while multi-decadal gyre-specific changes of the MOC have been simulated by Lozier et al., 2010. The MOC in the subpolar region is at maximum in 1986 as also indicated by our MOC index at $47^{\circ} \mathrm{N}$, while the MOC intensity-changes in the subtropics are delayed approximately by five years, with maximum in 1991. Following Eden and Greatbatch, 2003, and Böning et al., 2006, anomalies in the MOC would propagate from the SPF region towards the south following changes of the zonal density gradient due to spreading of LSW anomalies. Our time period between the intensification of the MOC at the frontal region and in the subtropics is in agreement with Eden and Greatbatch, 2003, who simulated an intensification of the MOC in the subtropics 4 years after the MOC maximum at the frontal region.

The relation between MOC, LSW and SPF in the NFB suggests the SPF index as an indicator of intensity changes of the MOC in the subtropics with a lead time of roughly 10 years: The southward displacement of the SPF after 1981 indicates the arrival of a positive LSW anomaly in the NFB (Fig. 10, central panel), which then intensifies the MOC in the subtropics to its maximum in 1991 (Fig. 11, lower left panel) as it flows with the DWBC. The SPF index, obtained from satellite altimetry or hydrographic measurements, can be used as complementary or alternative to the SPG intensity index (Fig. 4c) or DWBC transport at $53^{\circ} \mathrm{N}$ (Böning et al., 2006). The latter is confirmed by comparing the SPF to the volume transport of our modelled DWBC at $53^{\circ} \mathrm{N}$ (southward transport across a section next to the coast, depths larger than $2472 \mathrm{~m}$; not shown): This transport matches the SPG

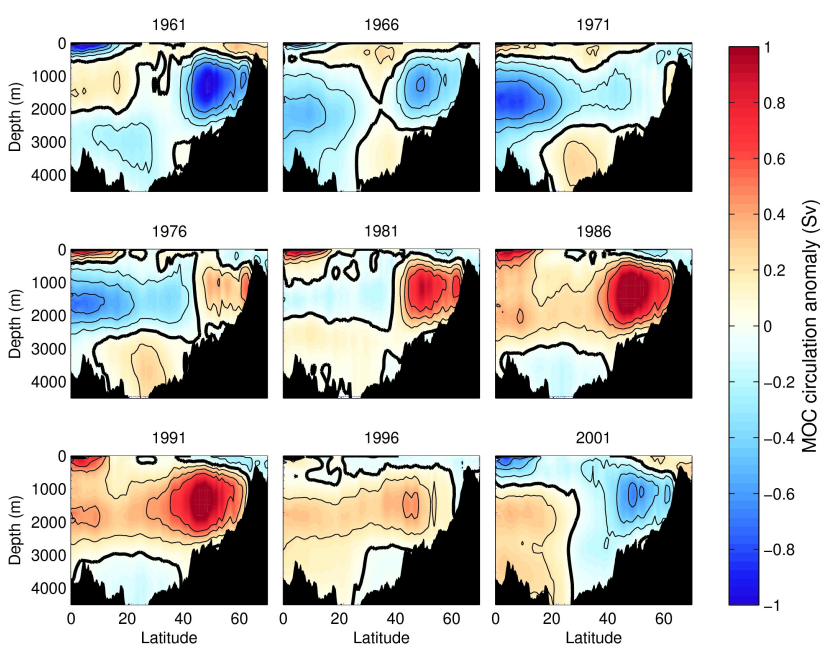

Fig. 11. Circulation anomaly of the MOC stream function (Sv). Positive anomalies (red) are clockwise and negative anomalies (blue) are anticlockwise.

index (Fig. 4c) and is, therefore, roughly simultaneous with the MOC in the subpolar region (Fig. 4b), conciliating our results with Böning et al., 2006: the intensification of the DWBC volume transport in the 1980s and 1990s would be related to more LSW in the west, larger zonal density gradient and MOC intensification.

\subsection{SPF displacement and MHT}

As the SPF displaces northwards the total MHT (Fig. 5a) reduces because the SPG is weak. When the SPF starts to displace southwards the positive overturning MHT (Fig. 5c) plays a larger role at the frontal region than the gyre MHT (Fig. 5b) and the total MHT reaches maximum in 1990s. Thus, changes of overturning MHT partially cancel with changes of gyre MHT in the frontal region: The reduction of gyre MHT near the SPF (Fig. 5b) due to the anti-cyclonic inter-gyre anomaly in the mid-1980s (Fig. 6) is compensated by the related northward displacement of the SPF (Fig. 5c). The resulting total MHT anomaly at the frontal region is almost zero at this time (Fig. 5a); similar compensations happened in the end of the 1950s and the earlier 1960s and the 2000s.

The gyre MHT anomalies (Fig. 5b) propagating southwards from ca. $55^{\circ} \mathrm{N}$ to the frontal region are a consequence of the southward propagation of circulation anomalies (Fig. 6). The overturning MHT anomalies (Fig. 5c) propagating southwards from the frontal region until $34^{\circ} \mathrm{N}$ (Sect. 4) are in agreement with the southward propagation of circulation anomalies of the MOC due to the flow of LSW with the DWBC. The overturning MHT at the front's latitude is roughly simultaneous with the SPF index (Fig. 4d): Negative values until the 1970s, maximum value in the 1980s and negative again from the middle 1990s. This is consistent 
with warm subtropical water displacing northwards in the NFB. Part of the anomalous heat in the frontal region seems to propagate northwards with the overturning circulation to $51^{\circ} \mathrm{N}$ in a period of 8 years. Eden and Willebrand, 2001, simulate an increase of MHT at the frontal region at decadal time scales, due to enhanced gyre and overturning circulations. Eden and Greatbatch, 2003, state that their MHT increases with positive NAO is mainly due to an MOC circulation anomaly in the subpolar North Atlantic. They argue that this MHT anomaly changes the sign of the SST dipole in the ocean and, thus, is responsible for the negative feedback with the atmosphere. However, the time evolution and magnitude of our total MHT (Fig. 5a) matches the gyre MHT (Fig. 5b) rather than the overturning MHT (Fig. 5c), suggesting that the contribution of the MOC to the total MHT anomalies in the subpolar region (excluding the frontal region) is minor at the multi-decadal time scale. This is the consequence of subpolar waters flowing southwards with a strengthened SPG.

However, the importance of horizontal circulation changes for the MHT anomalies revealed by our model could be exaggerated. For instance, our gyre MHT in the subpolar region is considerably larger compared to model simulations by Gulev et al., 2003, while overturning and gyre MHT components are similar south of the SPF. If our gyre MHT in the SPG region is overestimated, this could be a consequence of the too zonal NAC in our model and/or simulated MOW being warmer and saltier than in the observations, which makes the modelled zonal temperature differences in the subpolar region larger than the real ones.

\section{Summary and conclusions}

A novel data set (CliSAP data center) spanning 57 years of hydrographic observations in the North Atlantic evidences salinity anomalies related to a multi-decadal meridional displacement of the SPF in the NFB (Fig. 3a). While interannual displacements of the front in the western North Atlantic have been documented, the main contribution of the present study is the observation and modelling of a complete multi-decadal displacement cycle of the front, with minimum in the 1960s and 2000s and maximum around 1981. Since we have analysed only one complete front displacement, we would like to stress that ours is a case study with results reflecting the dynamics of the last 50 years only. Further research is needed to prove if the shown relations between WSC, LSW and the latitudinal position of the SPF at the multi-decadal time scale are of general nature.

Model results with MPIOM show that the SPF and associated NAC displacement is reflected by changes of a multi-decadal inter-gyre gyre, i.e. a circulation anomaly between the SPG and STG (Fig. 6). An anticyclonic intergyre gyre is related to a SPF north of its climatological position, indicating a northward expansion of the STG, while a cyclonic inter-gyre gyre is related to a SPF south of its climatological position, indicating a southward expansion of the SPG. A sensitivity experiment with variable wind and climatological heat fluxes yields the WSC component of the circulation (Fig. 7), while the residual between this experiment and the full forcing experiment yields the HFL component (Fig. 9). The contributions of WSC and HFL to circulation anomalies in the SPF region (grey dashed curve in Figs. 7 and 9) are of similar magnitude and seem to explain similar amounts of variability of the SPF displacement (Fig. 4h and i).

Sverdrup transport (Fig. 8) resembles the WSC component, supporting the notion of the WSC having an important effect on the SPF displacement also at the multi-decadal time scale. An anticyclonic WSC anomaly shifts the SPF northward, while a cyclonic anomaly leads to southward displacement. Spreading of LSW (Fig. 10) cause circulation anomalies in the SPF region (Fig. 9), suggesting an important role of LSW on the SPF displacement. A negative LSW thickness anomaly is related to a SPF north of its climatological position, while a positive LSW thickness anomaly is related to a SPF south of its climatological position. Therefore, the mean latitudinal position of the SPF in the NFB (SPF index) could be an indicator of the amount of LSW in the inter-gyre region.

The MOC is divided by the SPF in two regimes, with the subpolar regime having larger variability. The MOC intensifies as LSW flows with the DWBC into the NFB and beyond the SPF, increasing the zonal density gradient. The MOC has a maximum in the subpolar region five years after the SPF reaches its northernmost position, while, in the subtropical region, it lags by about 10 years. Therefore, the SPF index can be used as an index to predict the intensity of the MOC in the subpolar and subtropical regions at multi-decadal time scale.

Between 30 and $60^{\circ} \mathrm{N}$, the shift of the SPF is associated with the strongest signals in the gyre and overturning MHTs. The temperature anomalies linked to the SPF displacement in the NFB are associated with nearly opposite effects of gyre and overturning MHT (Fig. 5): while the gyre MHT decreases with an anticyclonic inter-gyre gyre (i.e. reduction of the cyclonic circulation north of the SPF) leading to a total MHT minimum in the late 1970s, the overturning MHT increases together with the intrinsically related northward displacement of the front, leading to a maximum of the total MHT in the early 1990s. In the subpolar region, MHT changes are dominated by the gyre component at the multidecadal time scale. This study emphasises that SPG strength and shape are the dominant factors for the MHT and thus ocean climate changes in the subpolar region of the North Atlantic.

Acknowledgements. We would like to thank our colleagues in the Max-Planck Institute for Meteorology for their kind help and suggestions: Daniela Matei, Jochem Marotzke, Aiko Vogt, Michael Botzet, Uwe Schulzweida, Malte Heinemann, Malte Müller and 
Zoltán Szüts. We appreciate valuable discussions with Carsten Eden (Institut für Meereskunde, Universität Hamburg) and the technical help of Irina Fast from the German Climate Computing Centre (DKRZ), where the model simulations have been carried out. I.N-R. thanks Anna Akimova (Institut für Seefischerei, Johann Heinrich von Thünen-Institut) for countless enriching discussions. The comments of two anonymous reviewers have improved this paper substantially. This study has been financed by the cluster of excellence "Integrated Climate System Analysis and Prediction" (CliSAP).

The service charges for this open access publication have been covered by the Max Planck Society.

Edited by: M. Hecht

\section{References}

Bacon, S.: Circulation and Fluxes in the North Atlantic between Greenland and Ireland, J. Phys. Oceanogr., 27, 1420-1435, 1997.

Belkin, I. M., Levitus, S., Antonov, J., and Malmberg, S.-A.: "Great Salinity Anomalies" in the North Atlantic, Prog. Oceanogr., 41, 1-68, 1998.

Bersch, M.: On the circulation of the northeastern North Atlantic, Deep-Sea Res. Pt. I, 42, 9, 1583-1607, 1995.

Bersch, M.: North Atlantic Oscillation-induced changes of the upper layer circulation in the northern North Atlantic Ocean, J. Geophys. Res., 107, C10, 1-11, 2002.

Bersch, M., Meincke, J., and Sy, A.: Interannual thermohaline changes in the northern North Atlantic 1991-1996, Deep-Sea Res. Pt. II, 46, 55-75, 1999.

Bersch, M., Yashayaev, I., and Koltermann, K. P.: Recent changes of the thermohaline circulation in the subpolar North Atlantic, Ocean Dynam., 57, 223-235, 2007.

Böning, C. W., Scheinert, M., Dengg, J., Biastoch, A., and Funk, A.: Decadal variability of subpolar gyre transport and its reverberation in the North Atlantic overturning, Geophys. Res. Lett., 33, L21S01, 1-5, 2006.

Boyer, T. P., Antonov, J. I., Garcia, H. E., Johnson, D. R., Locarnini, R. A., Mishonov, A. V., Pitcher, M. T., Baranova, O. K., and Smolyar, I. V.: World Ocean Database 2005, NOAA Atlas NESDIS 60, U.S. Department of Commerce, Silver Spring, MD., 2006.

Brauch, J. P. and Gerdes, R.: Response of the northern North Atlantic and Arctic oceans to a sudden change of the North Atlantic Oscillation, J. Geophy. Res., 110, C11018, 1-16, 2005.

Cayan, D. R.: Latent and sensible heat flux anomalies over the northern oceans: driving the sea surface temperature, J. Phys. Oceanogr., 22, 859-881, 1992.

Clarke, R. A.: Transport through the Cape Farewell-Flemish Cap section, Rapports et Procès-Verbaux des Réunions du Conseil International pour l'Exploration de la Mer, 185, 120-130, 1984.

Cunningham, S. A., Kanzow, T., Rayner, D., Baringer, M. O., Johns, W. E., Marotzke, J., Longworth, H. R., Grant, E. M., Hirschi, J. J.-M., Beal, L. M., Meinen, C. S., and Bryden, H. L.: Temporal Variability of the Atlantic Meridional Overturning Circulation at $26.5^{\circ} \mathrm{N}$, Nature, 317, 935-937, 2007.
Curry, R. G.: HydroBase2: A Database of Hydrographic Profiles and Tools for Climatological Analysis, Woods Hole Oceanographic Institution, USA, 2002.

Curry, R. G. and McCartney, M. S.: Ocean Gyre Circulation Changes Associated with the North Atlantic Oscillation, J. Phys. Oceanogr., 31, 3374-3400, 2001.

Curry, R. G., McCartney, M. S., and Joyce, T. M.: Oceanic transport of subpolar climate signals to mid-depth subtropical waters, Nature, 391, 5, 575-577, 1998.

Eden, C. and Greatbatch, R. J.: A Damped Decadal Oscillation in the North Atlantic Climate System, J. Climate, 16, 4043-4060, 2003.

Eden, C. and Jung, T.: North Atlantic Interdecadal Variability: Oceanic Response to the North Atlantic Oscillation (18651997), J. Climate, 14, 676-691, 2001.

Eden, C. and Willebrand, J.: Mechanism of Interannual to Decadal Variability of the North Atlantic Circulation, J. Climate, 14, 2266-2280, 2001.

Frankignoul, C., Coëtlogon, G. d., Joyce, T. M., and Dong, S.: Gulf Stream Variability and Ocean-Atmosphere Interactions, J. Phys. Oceanogr., 31, 3516-3529, 2001.

Frankignoul, C., Deshayes, J., and Curry, R.: The role of salinity in the decadal variability of the North Atlantic meridional overturning circulation, edited by: Frankignoul, C., Deshayes, J., Curry, R., Clim. Dynam., 33, 777-793, 2009.

Griffies, S. M., Biastoch, A., Böning, C., Bryan, F., Danabasoglu, G., Chassignet, E. P., England, M. H., Gerdes, R., Haak, H., Hallberg, R. W., Hazeleger, W., Jungclaus, J., Large, W. G., Madec, G., Pirani, A., Samuels, B. L., Scheinert, M., Gupta, A. S., Severijns, C. A., Simmons, H. L., Treguier, A. M., Winton, M., Yeager, S., Yin, J.: Coordinated Ocean-ice Reference Experiments (COREs), Ocean Modelling, 26, 1-46, 2009.

Gulev, S. K., Barnier, B., Knochel, H., and Molines, J.-M.: Water Mass Transformation in the North Atlantic and Its Impact on the Meridional Circulation: Insights from an Ocean Model Forced by NCEP-NCAR Reanalysis Surface Fluxes, J. Climate, 16, 19, 3085-3110, 2003.

Haak, H., Jungclaus, J., Mikolajewicz, U., and Latif, M.: Formation and propagation of great salinity anomalies, Geophys. Res. Lett., 30, 9, 1-4, 2003.

Häkkinen, S. and Rhines, P. B.: Decline of Subpolar North Atlantic Circulation During the 1990s, Science, 304, 555-559, 2004.

Häkkinen, S., Rhines, P. B., and Worthen, D. L.: Warm and saline events embedded in the meridional circulation of the northern North Atlantic, J. Geophys. Res., 116, C03006, doi:10.1029/2010JC006275, 2011.

Hátún, H., Sand $\varnothing$, A. B., Drange, H., Hansen, B., and Valdimarsson, H.: Influence of the Atlantic Subpolar Gyre on the Thermohaline Circulation, Science, 309, 1841-1843, 2005.

Herbaut, C. and Houssais, M.-N.: Response of the eastern North Atlantic subpolar gyre to the North Atlantic Oscillation, Geophys. Res. Lett., 36, L17607, 1-5, 2009.

Hurrell, J. W.: Decadal trends in the North Atlantic Oscillation: regional temperatures and precipitation, Science, 269, 676-679, 1995.

Joyce, T. M., Deser, C., and Spall, M. A.: The Relation between Decadal Variability of Subtropical Mode Water and the North Atlantic Oscillation, J. Climate, 13, 2550-2569, 2000.

Jungclaus, J. H., Keenlyside, N., Botzet, M., Haak, H., Luo, J.- 
J., Latif, M., Marotzke, J., Mikolajewicz, U., and Roeckner, E.: Ocean Circulation and Tropical Variability in the Coupled Model ECHAM5/MPI-OM, J. Climate - Special Section, 19, 8, 39523972, 2006.

Kalnay, E., Kanamitsu, M., Kistler, R., Collins, W., Deaven, D., Gandin, L., Iredell, M., Saha, S., White, G., Woollen, J., Zhu, Y., Chelliah, M., Ebisuzaki, W., Higgins, W., Janowiak, J., Mo, K. C., Ropelewski, C., Wang, J., Leetmaa, A., Reynolds, R., Jenne, R., and Joseph, D.: The NCEP/NCAR 40-Year Reanalysis Project, B. Am. Meteorol. Soc., 77, 3, 437-470, 1996.

Kanzow, T., Cunningham, S., Johns, W., Bryden, H., Hirschi, J., Baringer, M., Meinen, C., Chidicho, M. P., Marotzke, J., and Beal, L.: Continuous observations of the variability of the Atlantic meridional overturning circulation at $26.5^{\circ} \mathrm{N}$ : Major results and present challenges, Geophysical Research Abstracts, 12, 7074, 2010.

Kieke, D., Rhein, M., Stramma, L., Smethie, W. M., Bullister, J. L., and LeBel, D. A.: Changes in the pool of Labrador Sea Water in the subpolar North Atlantic, Geophys. Res. Lett., 34, L06605, doi:10.1029/2006GL028959, 2007.

Levitus, S.: Climatological atlas of the world ocean, International Research Institute for Climate Prediction (IRI), Internet webpage, http://iridl.ldeo.columbia.edu/SOURCES/.LEVITUS/, last access: 2009, 1994.

Lozier, M. S., Roussenov, V., Reed, M. S. C., and Williams, R. G.: Opposing decadal changes for the North Atlantic meridional overturning circulation, Nat. Geosci., 3, 728-734, 2010.

Marshall, J., Johnson, H., and Goodman, J.: A Study of the Interaction of the North Atlantic Oscillation with Ocean Circulation, J. Climate, 14, 1399-1421, 2001.
Marsland, S. J., Haak, H., Jungclaus, J. H., Latif, M., and Röske, F.: The Max-Planck-Institute global ocean/sea ice model with orthogonal curvilinear coordinates, Ocean Model., 5, 91-127, 2003.

McCartney, M. S., Worthington, L. V., and Raymer, M. E.: Anomalous water mass distributions at $55^{\circ} \mathrm{W}$ in the North Atlantic in 1977, J. Mar. Res., 38, 147-172, 1980.

Olsen, S. M., Hansen, B., Quadfasel, D., and Østerhus, S.: Observed and modelled stability of overflow across the GreenlandScotland ridge, Nature, 455, 519-523, 2008.

Rayner, N. A., Parker, D. E., Horton, E. B., Folland, C. K., Alexander, L. V., Rowell, D. P., Kent, E. C., and Kaplan, A.: Global analyses of sea surface temperature, sea ice, and night marine air temperature since the late nineteenth century, J. Geophys. Res., 108, D14, 4407, 1-22, 2003.

Röske, F.: The OMIP-Forcing based on ERA-15, http://www.omip. zmaw.de/omip/forcing365.php, last access: June, 2009, 2010.

Sverdrup, H. U.: Wind-Driven Currents in a Baroclinic Ocean; with Application to the Equatorial Currents of the Eastern Pacific, Proceedings of the National Academy of Sciences (USA), 33, 11, 318-326, 1947.

Sy, A., Rhein, M., Lazier, J. R. N., Koltermann, K. P., Meincke, J., Putzka, A., and Bersch, M.: Surprisingly rapid spreading of newly formed intermediate waters across the North Atlantic Ocean, Nature, 386, 675-679, 1997.

Yashayaev, I.: Hydrographic changes in the Labrador Sea, 1960 2005, Prog. Oceanogr., 73, 242-276, 2007.

Zhu, X. and Jungclaus, J.: Interdecadal variability of the meridional overturning circulation as an ocean internal mode, Clim. Dynam., 31, 731-741, 2008. 